\title{
Ultrasonic diagnosis combined with targeted ultrasound contrast agent improves diagnostic sensitivity of ultrasonic for non-small cell lung cancer patients
}

\author{
XIAOHONG ZHANG and CAN XIAO \\ Department of Ultrasound, Huaihe Hospital of Henan University, Kaifeng, Henan 475000, P.R. China
}

Received October 21, 2017; Accepted January 12, 2018

DOI: $10.3892 / \mathrm{etm} .2018 .6206$

\begin{abstract}
Non-small cell lung cancer (NSCLC) is one of the most prevalent human cancers, which is known for local growth, easily migration, long-distance invasion and reoccurrence. Targeted ultrasound (US) contrast combined with ultrasound for lung cancer diagnosis has been applied in the clinic. In the present study, a novel targeted ultrasound contrast agent containing chistosan $/ \mathrm{Fe}_{3} \mathrm{O}_{4}$-parceled bispecific antibody (TcBab) targeting carcino-embryonic antigen, vascular endothelial growth factor receptor was introduced, and the diagnostic accuracy and sensitivity was investigated in patients with NSCLC. A total of 384 patients with suspected NSCLC were recruited to investigate the accuracy of TcBab-ultrasound (TcBab-US) and ultrasound. Results demonstrated that TcBab-US improved sensitivity and may provide a novel protocol for diagnosing tumors in patients with suspected NSCLC at an early stage. Data analysis demonstrated that TcBab-US diagnosed 154 suspected patients with NSCLC, whereas ultrasound only diagnosed 84 suspected patients with NSCLC out of a total of 384 patients with suspected NSCLC $(\mathrm{P}<0.01)$. A dosage experiment revealed that the optimal dose of TcBab was $5 \mathrm{mg} / \mathrm{kg}$ for NSCLC patients. Pharmacodynamics analysis showed that TcBab may be metabolized within $16 \mathrm{~h}$ in serum of patients. Notably, early diagnosis determined by TcBab-US contributed to improvement of survival for NSCLC patients as determined by a comparison of the survival rate with the survival rate of patients who did not receive TcBab $(\mathrm{P}<0.05)$. In conclusion, these investigations suggested that TcBab improves the accuracy and diagnostic confidence of ultrasonic for the diagnosis of early-stage NSCLC, and may have potential application value in the clinic.
\end{abstract}

Correspondence to: Professor Xiaohong Zhang, Department of Ultrasound, Huaihe Hospital of Henan University, 8 Baogonghu North Road, Kaifeng, Henan 475000, P.R. China

E-mail: zhangxiaohonghenan@126.com

Key words: non-small cell lung cancer, ultrasound, chistosan/Fe3O4parceled bispecific antibody targeting, early diagnosis

\section{Introduction}

Non-small-cell lung cancer (NSCLC) is one of the most common tumors, which presents with an increasing trend and remains the most common cause of cancer-associated mortality worldwide $(1,2)$. Published literature has revealed that tumor growth migration and invasion are the most important features of NSCLC, which are characterized by local migration, metastasis and reoccurrence (3). A previous pathological study has suggested that NSCLC accounts for $\sim 80 \%$ of all lung cancer cases and classified adenocarcinoma, large cell carcinoma and squamous cell carcinoma as common types of NSCLC (4). A number of therapeutic strategies, such as immunotherapy, gene therapy, radiotherapy and chemotherapy, have been widely applied in clinical settings for the treatment of NSCLC (5-7); however, poor survival rates of patients with NSCLC have continued (8-10).

The majority of clinical patients with NSCLC are diagnosed at an advanced stage, which is the primary reason of rising death rate $(11,12)$. Although previous reports have introduced various diagnostic methods for NSCLC including ultrasound, computerized tomography and magnetic resonance imaging, ultrasound is the most widely used for diagnosis of NSCLC $(13,14)$. A previous study indicated that endobronchial ultrasound in combination with diagnostic bronchoscopy is highly effective in the diagnosis and staging of patients with lung cancer (15). Another previous study demonstrated that contrast-enhanced ultrasound improved enhancement pattern and cellular differentiation for hepatocellular carcinoma (16). In addition, contrast-enhanced ultrasound increased the diagnostic rate via observation of microvessel density and vascular endothelial growth factor expression, which may be valuable in the evaluation of early-stage breast cancer (17). In addition, microbubble ultrasound contrast agent has been reported to enhance the diagnostic rate for patients with suspected lung cancer in clinical settings $(18,19)$. These reports suggested that microbubble ultrasound contrast not only increases reflected signal, but also improves the diagnostic rate for patients with suspected lung cancer in the clinic.

Reports have suggested that the expression levels of vascular endothelial growth factor (VEGF) and VEGF receptor (VEGFR)-3 are overexpressed in NSCLC cells and this is associated with nodal status in operable NSCLC $(20,21)$. Higher expression levels of carcino-embryonic antigen (CEA) were 
observed in NSCLC cells, which is regarded as a prognostic indicator $(22,23)$. The present study introduced a novel targeted ultrasound contrast agent containing chistosan $/ \mathrm{Fe}_{3} \mathrm{O}_{4}$-parceled bispecific antibody (TcBab) targeting of CEA and VEGFR and investigated its efficiency for NSCLC diagnosis. The results suggested that TcBab-ultrasound (TcBab-US) may improve accuracy and sensitivity for patients with suspected NSCLC.

\section{Materials and methods}

Ethics statement. The present methodology was performed in strict accordance with the recommendations of the Guide for the Care and Use of Clinical Study of Pharmaceutical Administration Measures for Implementation of China (24). Employing nanoparticles loaded with superparamagnetic iron oxides and perfluoropentane in patients has been approved by the China Food and Drug Administration (HHRH20120514CD). The study was approved by the Ethics Committee of Huaihe Hospital of Henan University (Kiafeng, China). All patients were required to provide written informed consent prior to their inclusion.

Patients. A total of 384 patients with suspected NSCLC and 20 healthy volunteers were recruited for the present study at the Huaihe Hospital of Henan University between February 2010 and June 2016. The age of patients ranged from 32.8-67.5 years old. The number of male $(n=178)$ and female $(n=176)$ patients was approximately equal. The age of the healthy volunteers ranged from 26.9-54.1 years old (10 male and 10 female). The patients, including those with suspected NSCLC, were diagnosed with NSCLC at an early stage as described previously (25). Patients with lung cancer history were excluded from this study. A 60-month follow-up was performed on all patients. The characteristics of patients with suspected NSCLC were summarized in Table I.

Principles and settings of contrast-enhanced ultrasound. The ultrasound diagnosis system was used to analyze the efficacy of a targeted ultrasound contrast agent for the diagnosis of patients with suspected NSCLC using a preprogrammed setting. The preprogrammed setting was optimized to obtain the ideal image formation. The mechanical index was set at $0.2-0.4$ to avoid destruction of the fragile microbubbles containing nano-particles. The details of principles and settings of contrast-enhanced ultrasound were described in a previous study (26).

RT-qPCR analysis. Total RNAs from clinical tissues and cultured cells were extracted with TriZol ${ }^{\circledR}$ reagent (Takara Bio, Inc., Otsu, Japan) following the manufacturer's protocol. The RNA quality and quantity were determined by Nanodrop ${ }^{\circledR} 2000$ (Thermo Fisher Scientific, Inc., Waltham, MA, USA). Reverse transcription (RT) of first-strand cDNAs was performed using PrimeScript RT Master mix (Takara Bio, Inc.) according to the manufacturer's protocol. All PCR reactions were performed in an ABI PRISM 7900 Real-Time system (Thermo Fisher Scientific, Inc.) with the SYBR ${ }^{\circledR}$ Premix Ex Taq ${ }^{\mathrm{TM}}$ kit (Takara Bio, Inc.). For the PCR experiments the following forward and reverse primers were used: CEA forward, 5'-TGGCAGCAG TGACAGCAGCA-3' and reverse, 5'-TACGGAGGTGGAGTG
GGTGT-3'; VEGFR forward, 5'-AGCCGAGGAAGAACT ATGAAC-3' and reverse, 5'-ATTTGAGGGTGAGGAATG GG-3' and GAPDH forward, 5'-CAAAGGTGGATCAGATTC AAG-3' and reverse, 5'-GGTGAGCATTATCACCCAGAA-3'. The PCR conditions included an initial denaturation step of $94^{\circ} \mathrm{C}$ for $2 \mathrm{~min}$, followed by 30 cycles of $94^{\circ} \mathrm{C}$ for $30 \mathrm{sec}$, $59^{\circ} \mathrm{C}$ for $30 \mathrm{sec}, 72^{\circ} \mathrm{C}$ for $2 \mathrm{~min}$ and a final elongation step at $72^{\circ} \mathrm{C}$ for $10 \mathrm{~min}$. Taq DNA polymerase was purchased from Sigma-Aldrich (Merck KGaA, Darmstadt, Germany). GAPDH was used as the internal control to normalize gene expression. The relative gene expression levels were calculated using the $2^{-}{ }^{-\triangle \Delta C q}$ method (27). All experiments were repeated $\geq 3$ times. No negative control was used.

Ultrasound nanoparticles contrast agent. TcBab for targeting of CEAandVEGFR wereprovided by theBiologicalPharmaceutical Laboratory of Henan Medical University (Kaifeng, China). The construction of Chistosan/ $/ \mathrm{Fe}_{3} \mathrm{O}_{4}$-encapsulated $\mathrm{TcBab}$ was performed by using the covalent bond as described in a previous study (28). Novel Chistosan $/ \mathrm{Fe}_{3} \mathrm{O}_{4}$ nanoparticles-encapsulated $\mathrm{TcBab}$ was used to improve the imaging resolution ratio and diagnostic sensitivity in early-stage NSCLC diagnosis. TcBab contrast agent $(0.2 \mathrm{mg} / \mathrm{kg})$ was administered orally $60 \mathrm{~min}$ prior to contrast-enhanced ultrasound.

ELISA. Serum was isolated from peripheral blood $(10 \mathrm{ml})$ using centrifugation at $4,000 \mathrm{x} \mathrm{g}$ for $15 \mathrm{~min}$ at $4^{\circ} \mathrm{C}$. ELISA kits were used to determine interleukin CEA (cat. no. DY4128) and VEGFR (cat. no. MVR200B; both Bio-Rad Laboratories, Inc., Hercules, CA, USA). The procedures were performed according to the manufacturer's protocols.

Western blotting. A549, H1650 and MRC5 cells were purchased from the BeNa Culture Collection (Beijing Bei Na Chuanglian Biotechnology Research Institute, Beijing, China). All cells were cultured in Dulbecco's modified Eagle's medium (Thermo Fisher Scientific, Inc.) supplemented with $10 \%$ fetal bovine serum (Thermo Fisher Scientific, Inc.) in a humidified atmosphere containing $5 \% \mathrm{CO}_{2}$ at $37^{\circ} \mathrm{C}$.

Total protein was harvested from A549, H1650 and MRC5 cells cell samples $\left(1 \times 10^{8}\right)$ using a radioimmunoprecipitation buffer (Sigma-Aldrich; Merck KGaA) and protein concentrations were measured using a bicinchoninic acid protein assay kit (Thermo Fisher Scientific, Inc.). A total of $30 \mu \mathrm{g}$ protein was loaded per lane and separated by $10 \%$ SDS-PAGE and transferred to a polyvinylidene difluoride membranes using a semidry transfer system. Samples $(20 \mu \mathrm{g})$ were blocked with $5 \%$ bovine serum albumin (Gibco; Thermo Fisher Scientific, Inc.) for $1 \mathrm{~h}$ at $37^{\circ} \mathrm{C}$ and incubated with rabbit anti-human CEA (cat. no. 2383; 1:1,000) or VEGFR (cat. no. 2479; 1:1,000; both Cell Signaling Technology, Inc., Danvers, MA, USA) and anti-GAPDH (1:1,000; ab8245; Abcam, Cambridge, $\mathrm{UK}$ ) primary antibodies for $2 \mathrm{~h}$ at $37^{\circ} \mathrm{C}$. The membranes were then washed with PBS three times and incubated with a horseradish peroxidase-conjugated anti-rabbit immunoglobulin G secondary antibodies (1:5,000; cat. no. PV-6001; OriGene Technologies Inc., Rockville, MD, USA) for $2 \mathrm{~h}$ at $37^{\circ} \mathrm{C}$. Protein expression levels were visualized using a chemiluminescence detection system (LumiGLO; Cell Signaling Technology, Inc.). 
Table I. Characteristics of patients with non-small cell lung cancer.

\begin{tabular}{lcc}
\hline Characteristics & Male & Female \\
\hline Patients, $\mathrm{n}$ & 178 & 176 \\
Age, years & $35.4-64.2$ & $32.8-67.5$ \\
Medical history of cancer, $\mathrm{n}$ & 2 & 3 \\
Blood pressure, & $105.6 \pm 7.4$ & $108.8 \pm 10.5$ \\
mmHg (mean \pm SD) & & \\
Diagnosis (n) & & \\
Ultrasound & 178 & 176 \\
TcBab-US & 178 & 176 \\
\hline
\end{tabular}

$\mathrm{SD}$, standard deviation; TcBab-US, chistosan $/ \mathrm{Fe}_{3} \mathrm{O}_{4}$-parceled bispecific antibody-ultrasound.

Immunohistochemistry and histological staining. A549 cells were cultured in six-well plates at a density of $1 \times 10^{5}$ cells/well, in Eagle's Minimum Essential medium (EMEM) supplemented with $10 \%$ heat-inactivated fetal bovine serum (both Biowhittaker; Lonza Group, Ltd., Basel, Switzerland) for $12 \mathrm{~h}$ at $37^{\circ} \mathrm{C}$. The cells or tumor tissues were fixed with $10 \%$ methanol for $1 \mathrm{~h}$ at room temperature and blocked with phosphate buffered saline with Tween-20 containing 5\% non-fat milk for $1 \mathrm{~h}$ at room temperature. The cells were subsequently incubated with rabbit anti-human CEA $(1: 1,000)$ or VEGFR $(1: 1,000)$ primary antibodies for $2 \mathrm{~h}$ at $37^{\circ} \mathrm{C}$. Subsequently, fluorescein isothiocyanate-conjugated goat anti-rabbit secondary antibodies (1:5,000; cat. no. PV-6001; OriGene Technologies Inc.) were added for $2 \mathrm{~h}$ in the dark at $37^{\circ} \mathrm{C}$. Cells were then counterstained with DAPI (Sigma-Aldrich; Merck $\mathrm{KGaA}$, Darmstadt, Germany) for $2 \mathrm{~h}$ at $37^{\circ} \mathrm{C}$ and imaged under fluorescence microscopy in three fields of view (BX51; Olympus Corporation, Tokyo, Japan) at magnification, x40. Samples without secondary antibodies were used as the negative control for VEGFR and CEA expression. For histological staining, the tumor tissues were fixed in $10 \%$ buffered formalin for $1 \mathrm{~h}$ at $37^{\circ} \mathrm{C}$ followed by embedding in paraffin. Sections (4- $\mu \mathrm{m}$-thick) were then stained with hematoxylin-eosin for $2 \mathrm{~h}$ at $37^{\circ} \mathrm{C}$. All images were analyzed with ImageJ $1.44 \mathrm{p}$ software (National Institutes of Health, Bethesda, MD, USA). Subtypes of NSCLC were confirmed by two clinical pathologists as described previously (29).

Treatment of NSCLC patients diagnosed with TcBab-US. Early-stage NSCLC patients diagnosed with TcBab-US received different treatments including radiotherapy, chemotherapy, traditional Chinese medicine, biological therapy and comprehensive therapy as described previously (30). The median overall survival and median progression-free survival of NSCLC patients were analyzed in a previous study (31).

Viability assay. NSCLC cell viability assay was assessed using a Cell Counting Kit-8 (CCK-8; Beyotime Institute of Biotechnology, Haimen, China) according to the manufacturer's protocol. NSCLC cells $\left(1 \times 10^{3}\right)$ were seeded into 96-well plates and TcBab $(5 \mathrm{mg} / \mathrm{ml})$ or PBS (control) was added for
$48 \mathrm{~h}$ at $37^{\circ} \mathrm{C}$. CCK- 8 reagent was added to wells prior to the endpoint of incubation $(3 \mathrm{~h})$ at $37^{\circ} \mathrm{C}$. NSCLC cell viability was analyzed using a microplate reader at a wavelength of $570 \mathrm{~nm}$.

Scanning electron microscopy (SEM) and transmission electron microscopy (TEM) assays. The treated cells were fixed in $2.5 \%$ glutaraldehyde solution for $24 \mathrm{~h}$ at $4^{\circ} \mathrm{C}$. Following fixation, the cells were washed in $1.2 \mathrm{~mol} / 1$ phosphate buffer, which was changed three times within $3 \mathrm{~h}$. The cells were then fixed in $1 \%$ osmic acid for 1-1.5 $\mathrm{h}$ and washed in double-distilled water, which was replaced three times in $2 \mathrm{~h}$. The cells were dehydrated twice at room temperature using 50, 70, 80, 90 and $100 \%$ ethanol, for $20 \mathrm{~min}$ at each concentration. The ethanol solution was replaced with isoamyl acetate and the cells were placed in a critical point drying apparatus (a high-pressure hermetically sealed container) and liquid $\mathrm{CO}_{2}$ was added. The cells were then dried at a critical temperature of $31.8^{\circ} \mathrm{C}$ and 72.8 atm, sputter-coated with platinum using an IB-5 sputter coater with a $1.3 \mathrm{~nm}$ layer of platinum and observed using a Zeiss Field-Emission-Scanning-Electron-microscope (Zeiss $\mathrm{GmbH}$, Jena, Germany) at magnification, x400. The acceleration voltage was $1-5 \mathrm{kV}$.

The samples were fixed in $2.5 \%$ glutaric dialdehyde for $24 \mathrm{~h}$ at $4^{\circ} \mathrm{C}$. Following rinsing three times with phosphate-buffered saline (PBS), the lung cancer tissue was treated with $2 \%$ osmium tetroxide for $2 \mathrm{~h}$. It was subsequently dehydrated in a graded series of acetone following washing with PBS. Following dehydration, the lung cancer tissue was saturated in acetone/resin (1:1) at $37^{\circ} \mathrm{C}$ for $24 \mathrm{~h}$, embedded in Epon, polymerized in an oven at $60^{\circ} \mathrm{C}$ for $24 \mathrm{~h}$ and cut into semi-thin sections (1- $\mu \mathrm{m}$-thick). The TEM assay was performed using a Varian LEO 9220 (120 kV; Carl Zeiss AG, Oberkochen, Germany) instrument and analysis was performed using DigitalMicrograph software version 3.7 (Gatan Inc., Pleasanton, CA, USA) at magnification, $\mathrm{x} 200$. Samples were suspended in chloroform and sonicated at $100 \mathrm{kHz}$ for $5 \mathrm{~min}$ at $37^{\circ} \mathrm{C}$. A total of $2 \mu \mathrm{l}$ of the suspension was placed on a CF200-Cu-grid (Electron Microscopy Sciences, Hatfield, PA, USA) and allowed to dry.

Pharmacodynamics of TcBab. Plasma concentration of TcBab was analyzed in patients with suspected lung cancer after receiving TcBab contrast agent. Blood samples were collected from 32 participators at $0,6,12,18$ and $24 \mathrm{~h}$ following administrated with TcBab contrast agent. Plasma TcBab levels were determined via liquid chromatography-tandem mass spectrometry as previously described (32).

Statistical analysis. All data were presented as the mean \pm standard deviation of triplicate samples. Unpaired data was analyzed using Student's t-test and comparisons of data between multiple groups were analyzed using one-way analysis of variance with Tukey's post hoc test. Kaplan-Meier was used to estimate the survival rate during 60-months long-term observation. $\mathrm{P}<0.05$ was considered to indicate a statistically significant difference.

\section{Results}

Affinity of TcBab for CEA and VEGFR expression in NSCLC cells. CEA and VEGFR expression levels were analyzed in 

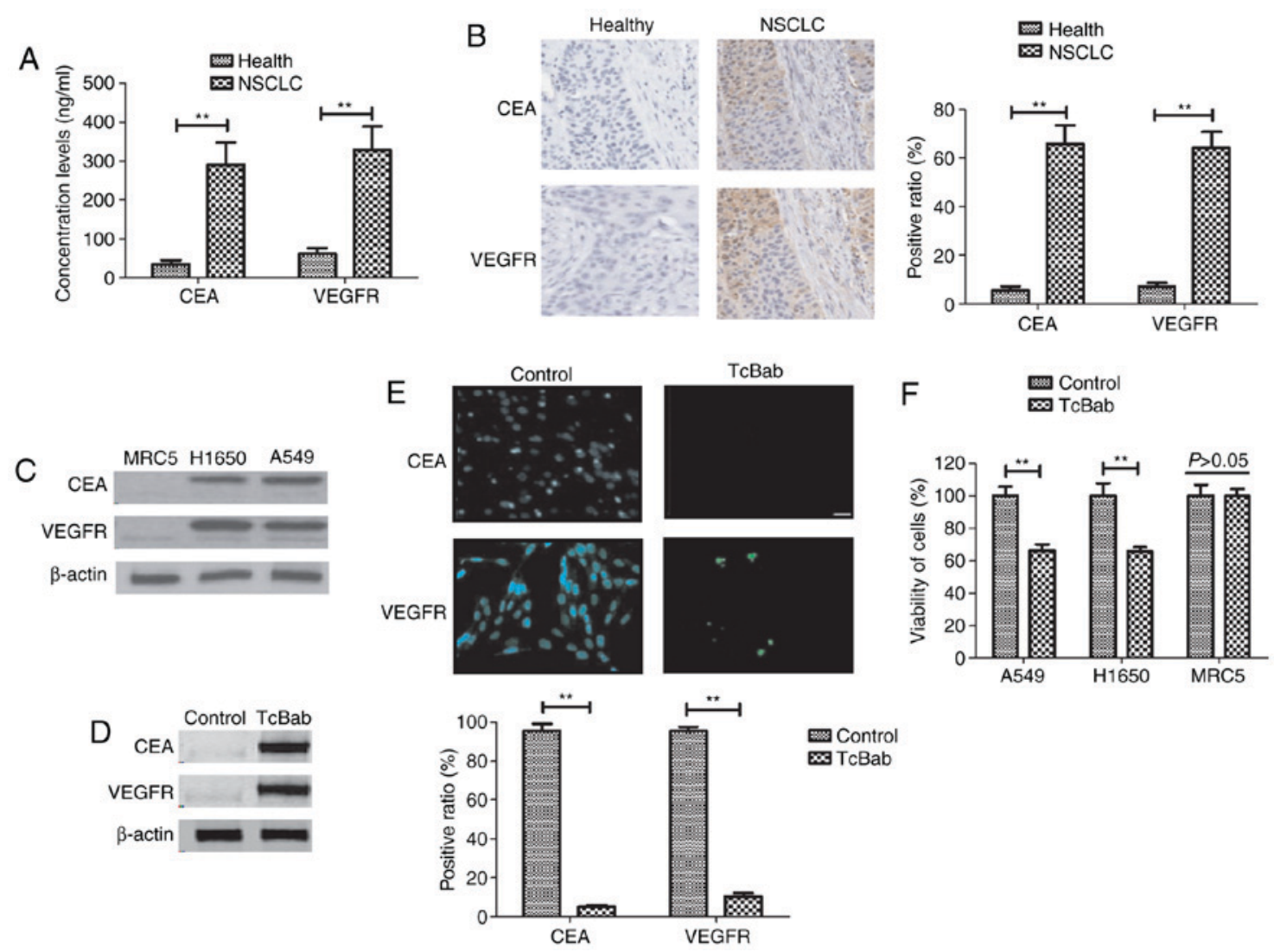

Figure 1. Affinity of TcBab for CEA and VEGFR expression in NSCLC cells. (A) Expression levels of CEA and VEGFR in NSCLC tissues and healthy tissues. (B) CEA and VEGFR expression levels were higher in NSCLC tumor tissue than in healthy tissue, as determined by immunohistochemistry staining. (C) Expression levels of CEA and VEGFR in A459 and H1650 NSCLC cells and the non-cancerous MRC5 cell line. (D) TcBab enhanced the expression levels of CEA and VEGFR. (E) Analysis of effects of TcBab on CEA and VEGFR expression in A549 cells. (F) TcBab decreased the viability of NSCLC cells. Data are presented as the mean \pm standard deviation. ${ }^{* *} \mathrm{P}<0.01$. $\mathrm{n}=6$ in each experiment. NSCLC, non-small cell lung cancer; CEA, carcino-embryonic antigen; VEGFR, vascular endothelial growth factor receptor; $\mathrm{TcBab}$, chistosan $/ \mathrm{Fe}_{3} \mathrm{O}_{4}$-parceled bispecific antibody.

tissues isolated from patients with NSCLC and healthy controls. It was revealed that CEA and VEGFR expression levels were significantly upregulated in NSCLC tissues compared with healthy tissues (Fig. 1A). It was demonstrated that CEA and VEGFR expression levels were markedly higher in NSCLC tumor tissue compared with normal tissue (Fig. 1B). The image gives a representation of the VEGFR and CEA staining using one sample from each group (Fig. 1B). Western blot analysis demonstrated that the protein expression of CEA and VEGFR were notably increased in A549 and H1650 cells compared to MRC5 cells (Fig. 1C). It was demonstrated that TcBab was able to upregulate CEA and VEGFR, as determined by western blotting, which decreased CEA and VEGFR expression in A549 cells (Fig. 1D). Immunofluorescence revealed that TcBab treatment decreased CEA and VEGFR expression in A549 cells compared with the non-treated cells (Fig. 1E). TcBab treatment $(5 \mathrm{mg} / \mathrm{ml})$ decreased the viability of NSCLC cell lines A549 and H1650, but did not affect viability of the non-cancerous MRC5 cell line (Fig. 1F). This data suggested that CEA and VEGFR are overexpressed in NSCLC cell lines and $\mathrm{TcBab}$ was able to enhance the expression levels of both CEA and VEGFR in NSCLC cells.

Characterization of TcBab. The hydrodynamic radius of the TcBab particles was calculated by SEM analysis (33). SEM revealed that a narrow particle distribution in the range from
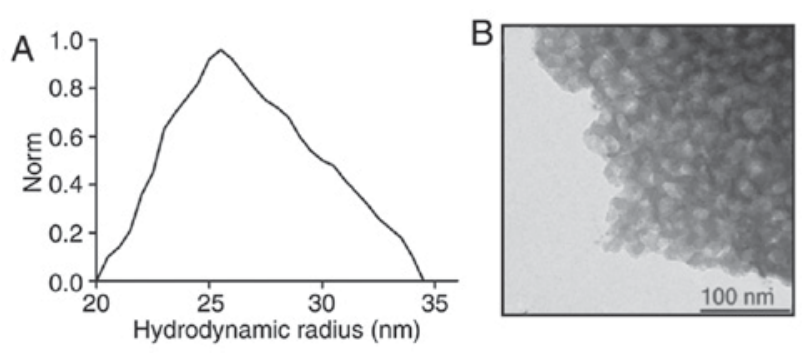

Figure 2. Particle size distribution of TcBab calculated by contin analysis. (A) Scanning electron microscopy analysis of the TcBab particle distribution in the range from 22 to $30 \mathrm{~nm}$. (B) TEM-images illustrates the association of pore density with $\mathrm{TcBab}$. TcBab, chistosan $/ \mathrm{Fe}_{3} \mathrm{O}_{4}$-parceled bispecific antibody.

20 to $35 \mathrm{~nm}$ was achieved (Fig. 2A). TEM-images illustrated the association of pore density with TcBab (Fig. 2B). These results indicated that TcBab is stable.

Efficacy of TcBab-US in early diagnosis for patients with suspected NSCLC. The dose of targeting nanoparticles contrast agent was identified as $30 \mathrm{mg} / \mathrm{kg}$ to achieve the optimum efficiency for diagnosing patients with suspected NSCLC (Table II). Efficacy of TcBab-US for patients with suspected NSCLC was investigated. As presented in Fig. 3, clinical outcomes revealed that TcBab-US diagnosed 154 suspected patients with NSCLC, whereas ultrasound diagnosed 
Table II. Confirmation of dosage of targeting nanoparticles contrast agent for patients with non-small cell lung cancer.

\begin{tabular}{lccc}
\hline Parameter & $5-15 \mathrm{mg} / \mathrm{kg}(\mathrm{n}=10)$ & $20-30 \mathrm{mg} / \mathrm{kg}(\mathrm{n}=14)$ & $35-45 \mathrm{mg} / \mathrm{kg}(\mathrm{n}=18)$ \\
\hline Signal intensity (HU) & $66.6 \pm 10.2$ & $83.4 \pm 12.2$ & $84.2 \pm 13.6$ \\
Sensitivity (\%) & $63.5 \pm 11.8$ & $84.5 \pm 10.4$ & $84.6 \pm 12.1$ \\
\hline
\end{tabular}

Data are presented as the mean \pm standard deviation.

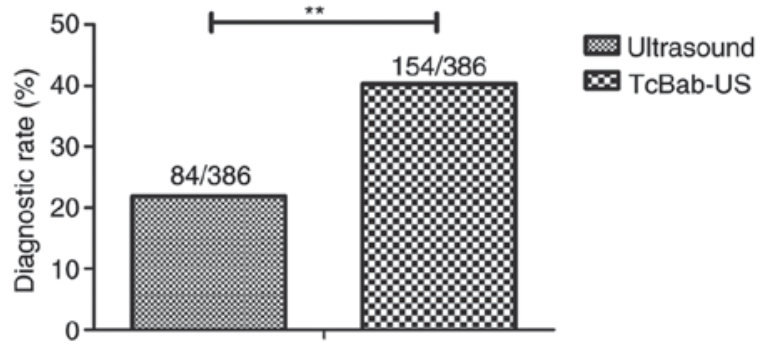

Figure 3. Diagnostic efficacy of TcBab-US for patients with suspected non-small cell lung cancer $(\mathrm{n}=384)$. Data are presented as the mean \pm standard deviation. ${ }^{* *} \mathrm{P}<0.01$. TcBab-US, chistosan $/ \mathrm{Fe}_{3} \mathrm{O}_{4}$-parceled bispecific antibody-ultrasound.

84 suspected patients with NSCLC out of a total of 384 patients $(\mathrm{P}<0.01)$. No obvious adverse effects of TcBab were observed in patients. These results suggested that TcBab contributed to improved accuracy and sensitivity for diagnosing patients with suspected NSCLC.

Pharmacodynamics of TcBab in plasma of patients with suspected NSCLC. To analyze metabolism of TcBab, the pharmacodynamics of TcBab in plasma in patients with suspected NSCLC were investigated. As presented in Fig. 4A, plasma concentration levels of TcBab were increased within $4 \mathrm{~h}$ and were metabolized within $16 \mathrm{~h}$. Results demonstrated that plasma concentration levels of CEA and VEGFR were decreased within $4 \mathrm{~h}$ and recovered to normal levels within $16 \mathrm{~h}$ in patients with suspected NSCLC (Fig. 4B and C). This clinical data suggested that TcBab-US may be a potential indicator for the diagnosis of early-stage patients with suspected NSCLC.

Histopathology confirms the accuracy of TcBab-US-diagnosis in patients with NSCLC. The present study further confirmed patients with suspected NSCLC via histopathology analysis. The representative NSCLC tissues demonstrated that TcBab-US diagnosed 46 patients suffering with large cell carcinoma out of a total of 384 patients, and ultrasound diagnosed 27 patients (Fig. 5A). A total of 74 patients were diagnosed with squamous cell carcinoma by TcBab-US, which was a significantly greater number compared with single ultrasound (34/384) diagnosis (Fig. 5B). Additionally, TcBab diagnosed 53 out of 384 patients with suspected NSCLC as having adenocarcinoma at early stage, compared with 23 patients in the ultrasound group (Fig. 5C). These data suggested that TcBab-US may be a reliable diagnostic method in diagnosing early-stage patients with suspected NSCLC.
Survival rate of patients with NSCLC diagnosed by TcBab-US. TcBab-US diagnosed early-stage NSCLC patients received different anti-cancer treatments. A summary of the anti-cancer treatments is presented in Table III. The results indicated that 128 patients were alive and tumor-free, 20 patients were still alive with tumor, and 6 patients succumbed in this investigation in a 60-month follow-up (Fig. 6A). It was also demonstrated that the median overall survival of NSCLC patients diagnosed by TcBab-US was 54.2 months (Fig. 6B), which is significantly higher compared with the mean survival of NSCLC patients who did not receive TcBab as reported previously $(\mathrm{P}<0.05)(34)$. Notably, the median progression-free survival was 44.8 months for patients with NSCLC (Fig. 6C). These data suggested that early-stage diagnosis via TcBab-US prolongs median overall survival in a 60-month follow-up for patients with NSCLC.

\section{Discussion}

NSCLC is one of the most prevalent malignant lung tumors, which has become a major public health problem and the leading cause of cancer-associated mortality worldwide (35). Data analysis has revealed that $\sim 120$ million new cases of lung cancer are diagnosed every year and that the proportion is increasing as the tumors become more common in younger patients (36). Notably, $>50 \%$ of patients diagnosed with NSCLC are at stage IIIB or IV disease, which is not only difficult to treat, but also increases pathologic material guiding systemic therapy (37). Therefore, a number of reports suggest that early diagnosis is beneficial for the treatment of NSCLC and may contribute to survival rate for patients in clinic $(25,38)$. Previous research has indicated that contrast-enhanced ultrasound has been widely applied in NSCLC diagnosis (39). The present study investigated the efficacy of a novel targeted ultrasound therapy that contained a nano-scale ultrasound contrast agent for the diagnosis of early-stage NSCLC patients. Findings demonstrated that TcBab enhances expression of target surface antigens in NSCLC cells, and also improves accuracy and sensitivity of ultrasound for patients with suspected NSCLC, which prolongs median progression-free survival and median overall survival in 60-month follow-up for patients with NSCLC.

A previous report demonstrated that VEGFR is overexpressed in NSCLC cell lines, which presents a potential molecular target for the next generation of targeted therapies in solid tumors (40). Zhang et al (41) previously demonstrated that a VEGFR-2 inhibitor may be regarded as an anti-cancer agent for the treatment of thyroid cancer, glioblastoma multiforme and NSCLC by inhibiting the activity of VEGFR. The present study demonstrated that binding with VEGFR via 

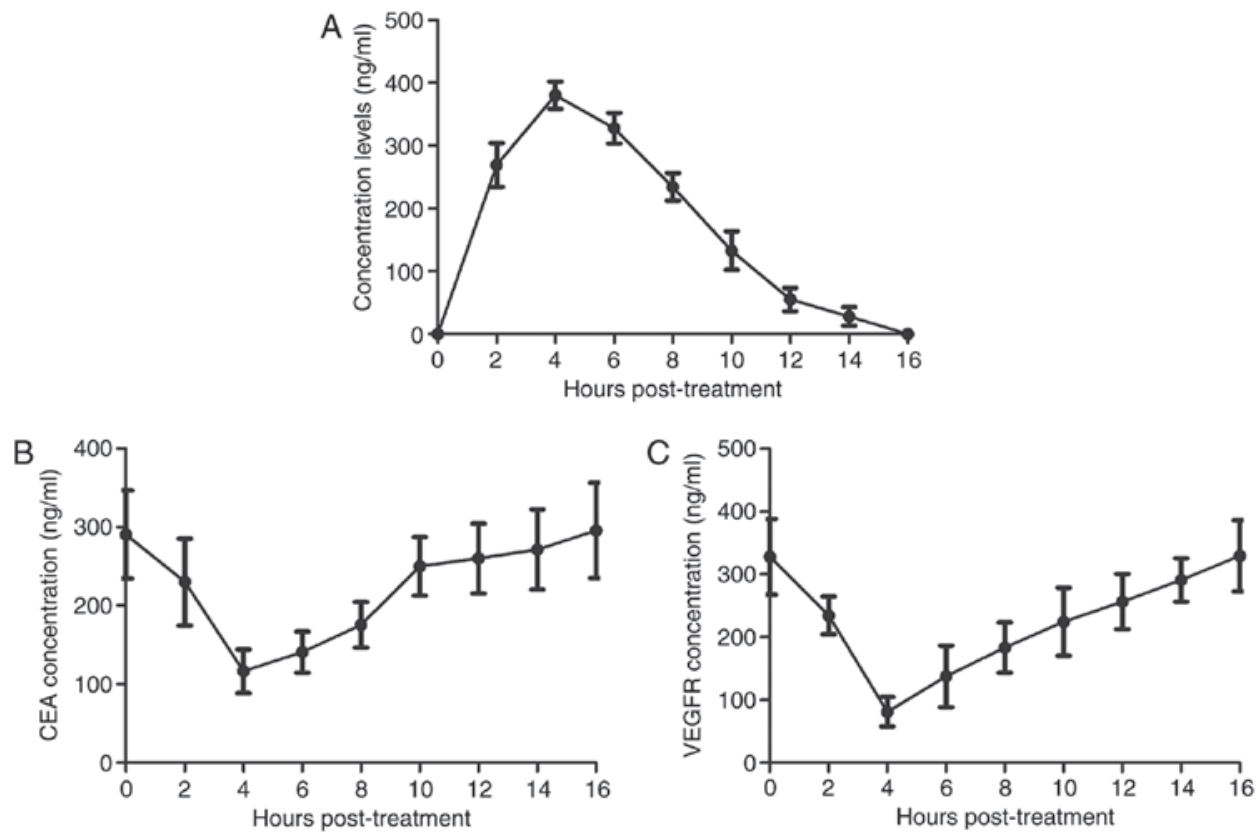

Figure 4. Pharmacodynamics of TcBab in plasma of patients with suspected NSCLC. (A) Plasma concentration levels of TcBab in patients with suspected NSCLC. Plasma concentration levels of (B) CEA and (C) VEGFR in patients with suspected NSCLC. $n=3$ in each group and experiments were repeated three times. NSCLC, non-small cell lung cancer; CEA, carcino-embryonic antigen; VEGFR, vascular endothelial growth factor receptor; TcBab, chistosan $/ \mathrm{Fe}_{3} \mathrm{O}_{4}$-parceled bispecific antibody. Data are presented as the mean \pm standard deviation.
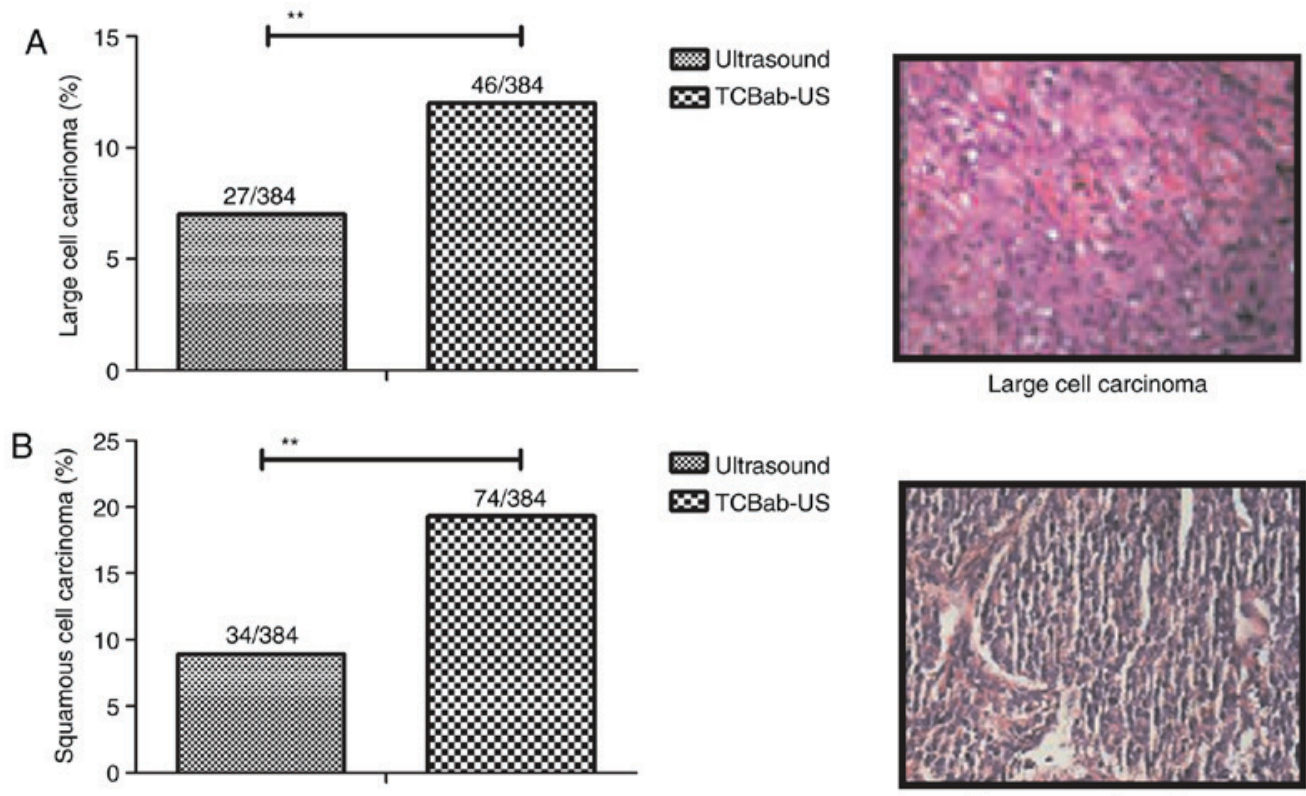

Squamous cell carcinoma
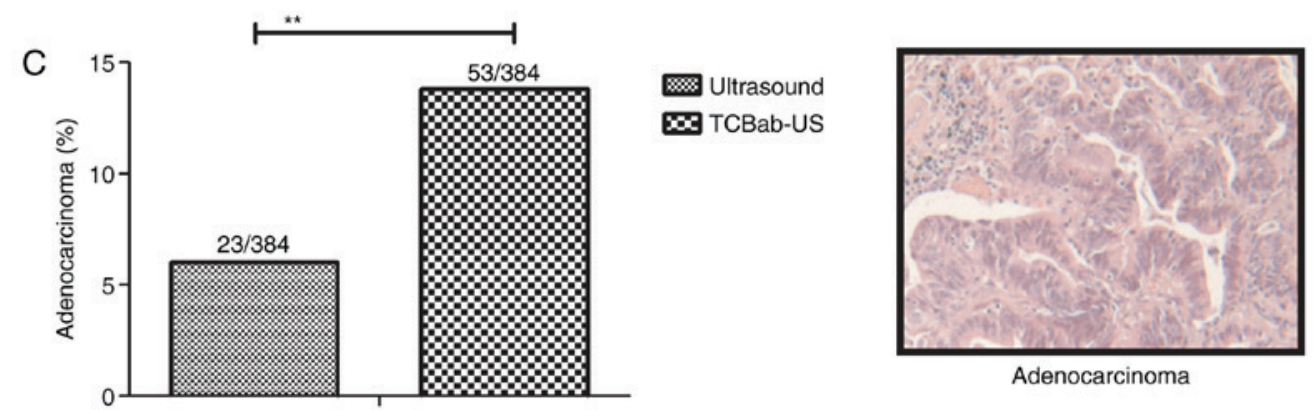

Figure 5. Histopathology confirms the accuracy of TcBab-US-diagnosed patients with NSCLC. (A) Diagnostic rate of large cell carcinoma by TcBab-US and ultrasound and a representative image of tumor morphology. (B) Diagnostic rate of squamous cell carcinoma by TcBab-US and ultrasound and a representative image of lung tumor morphology. (C) Diagnostic rate of adenocarcinoma by TcBab-US and ultrasound and a representative image of tumor morphology. Magnification, $\mathrm{x} 40 .{ }^{* *} \mathrm{P}<0.01$. NSCLC, non-small cell lung cancer; $\mathrm{TcBab}-\mathrm{US}$, chistosan $/ \mathrm{Fe}_{3} \mathrm{O}_{4}$-parceled bispecific antibody-ultrasound. 

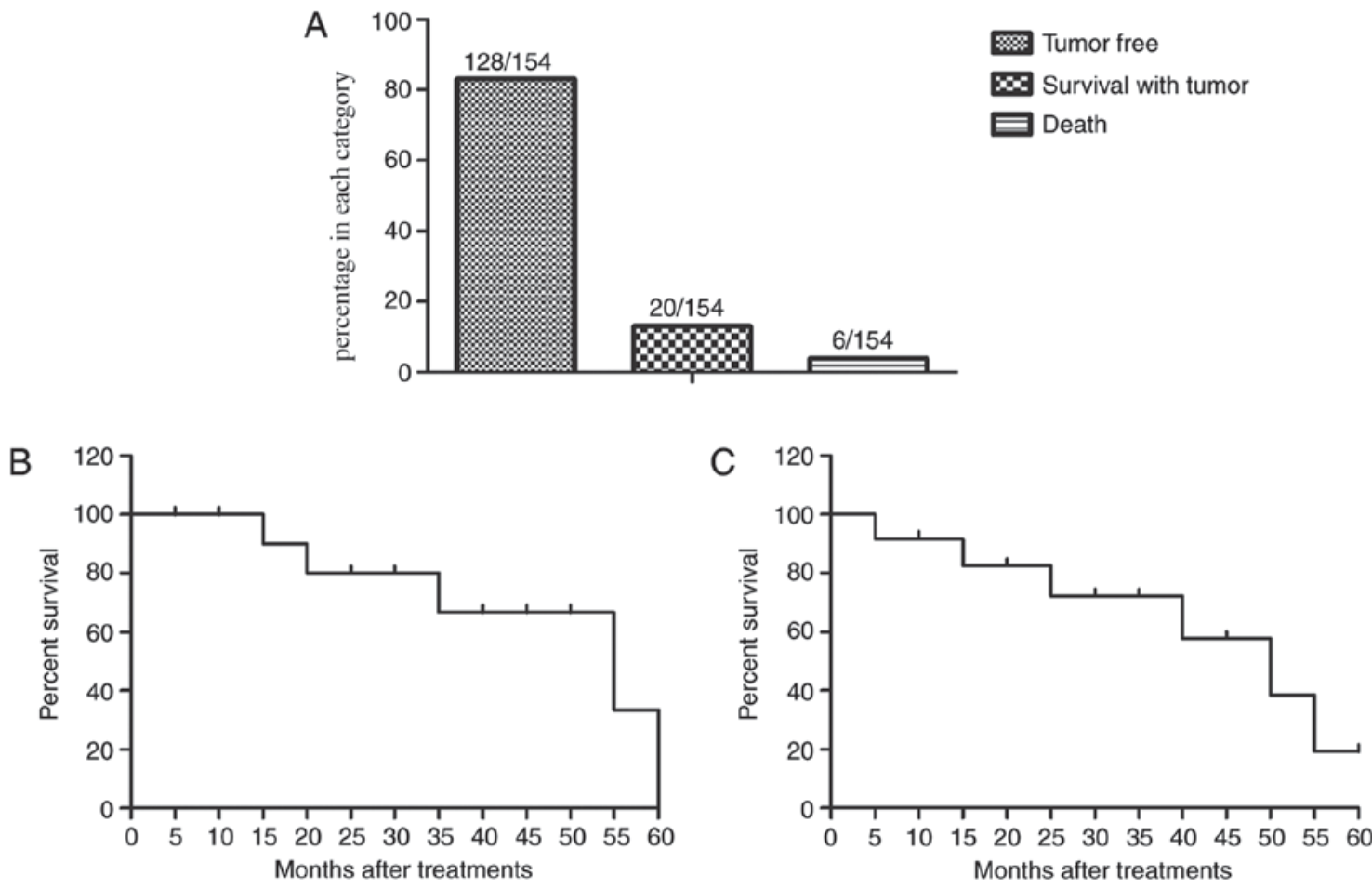

Figure 6. Overall survival of patients with NSCLC diagnosed by TcBab-US. (A) NSCLC patient percentage in each category, as diagnosed by TcBab-US in a 60-month follow-up. (B) Evaluation of the median overall survival of patients with lung cancer diagnosed by TcBab-US in early stage. Kaplan-Meier was used to estimate the survival rate during 60-months long-term observation. (C) Analysis of the median progression-free survival of lung cancer patients diagnosed by TcBab-US in early stage. Kaplan-Meier was used to estimate the survival rate during 60-months long-term observation. NSCLC, non-small cell lung cancer.

Table III. Treatment of patients with non-small cell lung cancer diagnosed by chistosan $/ \mathrm{Fe}_{3} \mathrm{O}_{4}$-parceled bispecific antibody-ultrasound.

\begin{tabular}{lcc}
\hline Characteristics & Male & Female \\
\hline Total patients (n) & 86 & 68 \\
Treatments (n) & & \\
Radiotherapy & 10 & 10 \\
Chemotherapy & 8 & 14 \\
Chinese medicine & 8 & 10 \\
Biological therapy & 12 & 8 \\
Comprehensive therapy & 48 & 26 \\
\hline
\end{tabular}

nano-scale ultrasound contrast agent TcBab enhanced ultrasonic signal feedback from lung nodes.

CEA is one of the surface markers of NSCLC cells, which is associated with survival in patients with stage IA-B NSCLC (42). Cedrés et al (43) previously suggested that serum tumor marker CEA is associated with worse prognosis in advanced NSCLC. In addition, Fiala et al (44) have indicated that CEA has a predictive role in patients with advanced-stage NSCLC treated with erlotinib. Furthermore, the diagnostic value of CEA for differentiation of early-stage NSCLC from benign lung disease has been investigated and discussed (45). The present study concurred with a previous report (46) and demonstrated that binding with CEA via nano-scale ultrasound contrast agent TcBab enhanced ultrasonic signal feedback from lung nidus.
At present, contrast medium has improved the diagnostic capability of ultrasound for a large number of human diseases $(47,48)$. de Ziegler (49) previously demonstrated that contrast ultrasound enhances the sensitivity and specificity assessment for uterine pathologies in the clinic. Wang et al (50) recently indicated that microflow imaging of contrast-enhanced ultrasound may be used to evaluate neovascularization in peripheral lung cancer. In the p-resent study, contrast target nano-scale ultrasound agent not only improved the resolution of ultrasound, but also improved the diagnostic sensitivity of ultrasound in the diagnosis of patients with early-stage NSCLC. Notably, contrast-enhanced target contrast agent ultrasound combined with ultrasound possesses clinical guidance value for the assessment of patients with early-stage NSCLC (51), which may have important clinical implications in NSCLC diagnosis.

\section{Acknowledgements}

Not applicable.

\section{Funding}

No funding was received.

\section{Availability of data and materials}

The datasets used and/or analyzed during the current study are available from the corresponding author on reasonable request. 


\section{Authors' contributions}

$\mathrm{XZ}$ and CX designed the study. XZ performed the experiments and analysed the data.

\section{Ethics approval and consent to participate}

All patients were required to provide written informed consent prior to their inclusion. The study was approved by the Ethics Committee of Huaihe Hospital of Henan University (Kiafeng, China).

\section{Consent for publication}

All patients provided written informed consent for the publication of their data.

\section{Competing interests}

The authors declare that they have no competing interests.

\section{References}

1. Ren Z, Zhou S, Liu Z and Xu S: Randomized controlled trials of induction treatment and surgery versus combined chemotherapy and radiotherapy in stages IIIA-N2 NSCLC: A systematic review and meta-analysis. J Thorac Dis 7: 1414-1422, 2015.

2. Tsim S, O'Dowd CA, Milroy R and Davidson S: Staging of non-small cell lung cancer (NSCLC): A review. Respir Med 104: 1767-1774, 2010.

3. Yang Y, Xie Y and Xian L: Breast cancer susceptibility gene 1 (BRCA1) predict clinical outcome in platinum- and toxal-based chemotherapy in non-small-cell lung cancer (NSCLC) patients: A system review and meta-analysis. J Exp Clin Cancer Res 32: $15,2013$.

4. Detterbeck FC, Chansky K, Groome P, Bolejack V, Crowley J, Shemanski L, Kennedy C, Krasnik M, Peake M and Rami-Porta R; IASLC Staging and Prognostic Factors Committee, Advisory Boards, and Participating Institutions: The IASLC lung cancer staging project: Methodology and validation used in the development of proposals for revision of the stage classification of NSCLC in the forthcoming (Eighth) edition of the TNM classification of lung cancer. J Thorac Oncol 11: 1433-1446, 2016.

5. Santiago A, Barczyk S, Jelen U, Engenhart-Cabillic R and Wittig A: Challenges in radiobiological modeling: can we decide between LQ and LQ-L models based on reviewed clinical NSCLC treatment outcome data? Radiat Oncol 11: 67, 2016.

6. Gelsomino F, Ambrosini V, Melotti B, Sperandi F and Ardizzoni A: Pitfalls in oncology: Osteoblastic response mimicking bone progression during ceritinib treatment in ALK-rearranged NSCLC. J Thorac Oncol 11: e99-e101, 2016.

7. Bronte G, Passiglia F, Galvano A and Russo A: Anti-angiogenic drugs for second-line treatment of NSCLC patients: Just new pawns on the chessboard? Expert Opin Biol Ther 16: 1-5, 2016.

8. Xie FJ, Lu HY, Zheng QQ, Qin J, Gao Y, Zhang YP, Hu X and Mao WM: The clinical pathological characteristics and prognosis of FGFR1 gene amplification in non-small-cell lung cancer: A meta-analysis. Onco Targets Ther 9: 171-181, 2016.

9. Moro-Sibilot D, Smit E, de Castro Carpeño J, Lesniewski-Kmak K, Aerts JG, Villatoro R, Kraaij K Nacerddine K, Dyachkova Y, Smith KT, et al: Non-small cell lung cancer patients with brain metastases treated with first-line platinum-doublet chemotherapy: Analysis from the European FRAME study. Lung Cancer 90: 427-432, 2015.

10. Lim SH, Sun JM, Lee SH, Ahn JS, Park K and Ahn MJ: Pembrolizumab for the treatment of non-small cell lung cancer. Expert Opin Biol Ther 16: 397-406, 2016.

11. Calabuig-Fariñas S, Lewintre EJ, Mayo-De-Las-Casas C Cordellat AB, Molina-Vila MA, Rosell R and Camps C: 149P: The role of CTCs and cfDNA for diagnosis and monitoring of EGFR mutations in advanced NSCLC patients. J Thorac Oncol 11 (4 Suppl): S123, 2016.
12. Mascalchi M, Falchini M, Maddau C, Salvianti F, Nistri M, Bertelli E, Sali L, Zuccherelli S, Vella A, Matucci M, et al: Prevalence and number of circulating tumour cells and microemboli at diagnosis of advanced NSCLC. J Cancer Res Clin Oncol 142: 195-200, 2016.

13. Koh MS, Tee A, Wong P, Antippa P and Irving LB: Advances in lung cancer diagnosis and staging: endobronchial ultrasound. Intern Med J 38: 85-89, 2008

14. Kuo CH, Lin SM, Chen HC, Chou CL, Yu CT and Kuo HP: Diagnosis of peripheral lung cancer with three echoic features via endobronchial ultrasound. Chest 132: 922-929, 2007.

15. Ernst A, Feller-Kopman D and Herth FJ: Endobronchial ultrasound in the diagnosis and staging of lung cancer and other thoracic tumors. Semin Thorac Cardiovasc Surg 19: 201-205, 2007.

16. Loria F, Loria G, Basile S, Crea G, Randazzo D and Frosina L: Contrast-enhanced ultrasound of hepatocellular carcinoma: correlation between enhancement pattern and cellular differentiation on histopathlogy. Updates Surg 64: 247-255, 2012.

17. Liu H, Jiang Y, Dai Q, Zhu Q, Wang L and Lu J: Peripheral enhancement of breast cancers on contrast-enhanced ultrasound: Correlation with microvessel density and vascular endothelial growth factor expression. Ultrasound Med Biol 40: 293-299, 2014.

18. Duguay S, Wagner JM, Zheng W, Ling J, Zhao LC, Allen KS, North JC and Deb SJ: Ultrasound-guided needle biopsy of neck lymph nodes in patients with suspected lung cancer: Are the specimens sufficient for complete pathologic evaluation to guide patient management? Ultrasound Q 33: 133-138, 2016.

19. Castro-Pocas FM, Araüjo TP, Ferreira ML and Saraiva MM: The role of endoscopic ultrasound in a case of lung cancer with jaundice. Endosc Ultrasound, Nov 8, 2016 (Epub ahead of print).

20. Loriot Y, Mordant P, Dorvault N, De la motte Rouge T, Bourhis J, Soria JC and Deutsch E: BMS-690514, a VEGFR and EGFR tyrosine kinase inhibitor, shows anti-tumoural activity on non-small-cell lung cancer xenografts and induces sequence-dependent synergistic effect with radiation. $\mathrm{Br} \mathrm{J}$ Cancer 103: 347-353, 2010.

21. Donnem T, Al-Shibli K, Al-Saad S, Delghandi MP, Busund LT and Bremnes RM: VEGF-A and VEGFR-3 correlate with nodal status in operable non-small cell lung cancer: Inverse correlation between expression in tumor and stromal cels. Lung Cancer 63: 277-283, 2009.

22. Szturmowicz M, Rudzinski P, Kacprzak A, Langfort R, Bestry I, Broniarek-Samson B and Orłowski T: Prognostic value of serum C-reactive protein (CRP) and cytokeratin 19 fragments (Cyfra 21-1) but not carcinoembryonic antigen (CEA) in surgically treated patients with non-small cell lung cancer. Pneumonol Alergol Pol 82: 422-429, 2014.

23. Dai H, Liu J, Liang L, Ban C, Jiang J, Liu Y, Ye Q and Wang C: Increased lung cancer risk in patients with interstitial lung disease and elevated CEA and CA125 serum tumour markers. Respirology 19: 707-713, 2014.

24. Xing W, Zhigang W, Bing H, Haitao R, Pan L, Chuanshan X, Yuanyi $\mathrm{Z}$ and Ao L: Targeting an ultrasound contrast agent to folate receptors on ovarian cancer cells: Feasibility research for ultrasonic molecular imaging of tumor cels. J Ultrasound Med 29: 609-614, 2010.

25. Vansteenkiste J, De Ruysscher D, Eberhardt WE, Lim E, Senan S, Felip E and Peters S; ESMO Guidelines Working Group: Early and locally advanced non-small-cell lung cancer (NSCLC): ESMO Clinical Practice Guidelines for diagnosis, treatment and follow-up. Ann Oncol 24 (Suppl 6): vi89-vi98, 2013.

26. Schinkel AF, Kaspar M and Staub D: Contrast-enhanced ultrasound: Clinical applications in patients with atherosclerosis. Int J Cardiovasc Imaging 32: 35-48, 2016.

27. Livak KJ and Schmittgen TD: Analysis of relative gene expression data using real-time quantitative PCR and the 2(-Delta Delta C(T)) method. Methods 25: 402-408, 2001.

28. Chen CL, Hu GY, Mei Q, Qiu H, Long GX and Hu GQ: Epidermal growth factor receptor-targeted ultra-small superparamagnetic iron oxide particles for magnetic resonance molecular imaging of lung cancer cells in vitro. Chin Med J (Engl) 125: 2322-2328, 2012.

29. Sutiman N, Tan SW, Tan EH, Lim WT, Kanesvaran R, Ng QS, Jain A, Ang MK, Tan WL, Toh CK and Chowbay B: EGFR mutation subtypes influence survival outcomes following first-line gefitinib therapy in advanced Asian NSCLC patients. J Thorac Oncol. 12: 529-538, 2017. 
30. Zhou JG, Tian X, Wang X, Tian JH, Wang Y, Wang F, Zhang Y and Ma H: Treatment on advanced NSCLC: Platinum-based chemotherapy plus erlotinib or platinum-based chemotherapy alone? A systematic review and meta-analysis of randomised controlled trials. Med Oncol 32: 471, 2015.

31. Angelov KG, Vasileva MB, Grozdev KS, Sokolov MB and Todorov G: Clinical and pathological characteristics, and prognostic factors for gastric cancer survival in 155 patients in Bulgaria. Hepatogastroenterology 61: 2421-2444, 2014.

32. Granja RH, Salerno AG, de Lima AC, Montalvo C, Reche KV, Giannotti FM and Wanschel AC: Liquid chromatography/tandem mass spectrometry method to determine boldenone in bovine liver tissues. J AOAC Int 97: 1476-1480.

33. Kong Y, Wang P, Liu S, Zhao G and Peng Y: SEM analysis of the interfacial transition zone between cement-glass powder paste and aggregate of mortar under microwave curing. Materials (Basel) 9: pii: E733, 2016.

34. Gainor JF, Tan DS, De Pas T, Solomon BJ, Ahmad A, Lazzari C, de Marinis F, Spitaleri G, Schultz K, Friboulet L, et al: Progression-free and overall survival in ALK-Positive NSCLC patients treated with sequential crizotinib and ceritinib. Clin Cancer Res 21: 2745-2752, 2015.

35. Magnuson WJ, Yeung JT, Guillod PD, Gettinger SN, Yu JB and Chiang VL: Impact of deferring radiation therapy in patients with epidermal growth factor receptor-mutant non-small cell lung cancer who develop brain metastases. Int $\mathbf{J}$ Radiat Oncol Biol Phys 95: 673-679, 2016.

36. Thill PG, Goswami P, Berchem G and Domon B: Lung cancer statistics in Luxembourg from 1981 to 2008. Bull Soc Sci Med Grand Duche Luxemb 2: 43-55, 2011.

37. Reck M, Popat S, Reinmuth N, De Ruysscher D, KerrKM and Peters S; ESMO Guidelines Working Group: Metastatic non-small-cell lung cancer (NSCLC): ESMO Clinical Practice Guidelines for diagnosis, treatment and follow-up. Ann Oncol 25 (Suppl 3): iii27-iii39, 2014.

38. Yang S, Nan Y, Tian Y, Zhang W, Zhou B, Bu L, Huo S, Chen G, $\mathrm{Yu}$ J and Zheng S: Study of distinct protein profiles for early diagnosis of NSCLC using LCM and SELDI-TOF-MS. Med Oncol 25: 380-386, 2008

39. Vázquez-Sequeiros E, González-Panizo-Tamargo F, Barturen Á, Calderón Á, Esteban JM, Fernández-Esparrach G, Gimeno-García A, Ginés A, Lariño J, Pérez-Carreras M, et al: The role of endoscopic ultrasound guided fine needle aspiration (EUS-FNA) in non small cell lung cancer (NSCLC) patients: SEED-SEPD-AEG joint guideline. Rev Esp Enferm Dig 105 215-224, 2013.

40. Pennell NA and Lynch TJ Jr: Combined inhibition of the VEGFR and EGFR signaling pathways in the treatment of NSCLC. Oncologist 14: 399-411, 2009.
41. Zhang Y, Guessous F, Kofman A, Schiff D and Abounader R XL-184, a MET, VEGFR-2 and RET kinase inhibitor for the treatment of thyroid cancer, glioblastoma multiforme and NSCLC. IDrugs 13: 112-121, 2010.

42. Ishikawa H, Satoh H, Yamashita YT, Ohtsuka M and Sekizawa K: CEA and survival in patients with stage IA-B NSCLC. Thorac Cardiovasc Surg 50: 253, 2002.

43. Cedrés S, Nuñez I, Longo M, Martinez P, Checa E, Torrejón D and Felip E: Serum tumor markers CEA, CYFRA21-1, and CA-125 are associated with worse prognosis in advanced non-small-cell lung cancer (NSCLC). Clin Lung Cancer 12: 172-179, 2011.

44. Fiala O, Pesek M, Finek J, Benesova L, Minarik M, Bortlicek Z and Topolcan O: Predictive role of CEA and CYFRA 21-1 in patients with advanced-stage NSCLC treated with erlotinib. Anticancer Res 34: 3205-3210, 2014.

45. Chen F, Wang XY, Han XH, Wang H and Qi J: Diagnostic value of Cyfra21-1, SCC and CEA for differentiation of early-stage NSCLC from benign lung disease. Int J Clin Exp Med 8 11295-11300, 2015.

46. Kallmayer M, Tsantilas P, Zieger C, Ahmed A, Söllner H, Zimmermann $\mathrm{A}$ and Eckstein $\mathrm{H}$ : Ultrasound surveillance after CAS and CEA: What's the evidence? J Cardiovasc Surg (Torino) 55 (2 Suppl 1): S33-S41, 2014.

47. Ignee A, Schuessler G, Cui XW and Dietrich CF: Intracavitary contrast medium ultrasound-different applications, a review of the literature ad future prospects. Ultraschall Med 34: 504-525; quiz 526-528, 2013 (In German).

48. Lee SH, Kim JM, Chan V, Kim HJ and Kim HI: Ultrasoundguided cervical periradicular steroid injection for cervical radicular pain: Relevance of spread pattern and degree of penetration of contrast medium. Pain Med 14: 5-13, 2013.

49. de Ziegler D: Contrast ultrasound: A simple-to-use phase-shifting medium offers saline infusion sonography-like images. Fertil Steril 92: 369-373, 2009.

50. Wang S, Yang W, Fu JJ, Sun Y, Zhang H, Bai J, Chen MH and Yan K: Microflow imaging of contrast-enhanced ultrasound for evaluation of neovascularization in peripheral lung cancer. Medicine (Baltimore) 95: e4361, 2016

51. Chopra A: ${ }^{125}$ I-Labeled heparin-binding peptides that target heparan sulfate proteoglycans for the in vivo imaging of peripheral amyloidosis. Molecular Imaging and Contrast Agent Database (MICAD) [Internet]. National Center for Biotechnology Information (US), Bethesda, MD, 2011. 